\title{
The impact of heatwaves on emergency department visits in Brisbane, Australia: a time series study
}

\author{
Ghasem Sam Toloo*, Weiwei Yu, Peter Aitken, Gerry FitzGerald and Shilu Tong
}

\begin{abstract}
Introduction: The acute health effects of heatwaves in a subtropical climate and their impact on emergency departments (ED) are not well known. The purpose of this study is to examine overt heat-related presentations to EDs associated with heatwaves in Brisbane.

Methods: Data were obtained for the summer seasons (December to February) from 2000-2012. Heatwave events were defined as two or more successive days with daily maximum temperature $\geq 34^{\circ} \mathrm{C}$ (HWD1) or $\geq 37^{\circ} \mathrm{C}$ (HWD2). Poisson generalised additive model was used to assess the effect of heatwaves on heat-related visits (International Classification of Diseases (ICD) 10 codes T67 and X30; ICD 9 codes 992 and E900.0).

Results: Overall, 628 cases presented for heat-related illnesses. The presentations significantly increased on heatwave days based on HWD1 (relative risk $(R R)=4.9,95 \%$ confidence interval $(C l): 3.8,6.3$ ) and HWD2 (RR $=18.5,95 \%$ Cl: 12.0, 28.4). The RRs in different age groups ranged between 3-9.2 (HWD1) and 7.5-37.5 (HWD2). High acuity visits significantly increased based on HWD1 ( $R R=4.7,95 \% \mathrm{Cl}: 2.3,9.6)$ and HWD2 (RR $=81.7,95 \% \mathrm{Cl}: 21.5,310.0)$. Average length of stay in ED significantly increased by $>1$ hour (HWD1) and $>2$ hours (HWD2).

Conclusions: Heatwaves significantly increase ED visits and workload even in a subtropical climate. The degree of impact is directly related to the extent of temperature increases and varies by socio-demographic characteristics of the patients. Heatwave action plans should be tailored according to the population needs and level of vulnerability. EDs should have plans to increase their surge capacity during heatwaves.
\end{abstract}

\section{Introduction}

The effects of heatwaves and hot temperatures on mortality [1-7] and morbidity [8-11] are increasingly recognised. However, the type and magnitude of the effects vary from one place to another, depending on many factors including the climate, socio-demographic characteristics, community preparedness, and resilience of the population.

Previous studies show that high temperature and heatwaves are associated with higher mortality and years of life lost [12-15], as well as with increased risks of ambulance call-outs [16] and hospital admissions $[14,17,18]$ due to heat-exacerbated health conditions such as cardiovascular disease (CVD), renal disease, diabetes, and non-external causes in general. However, the more direct impact of heatwaves on heat-related conditions such as heatstroke, heat

\footnotetext{
* Correspondence: sam.toloo@qut.edu.au

School of Public Health and Social Work, Queensland University of Technology, Victoria Park Road, Kelvin Grove, QLD 4059, Australia
}

exhaustion, and dehydration, classified under external causes of diseases by the International Classification of Diseases (ICD), is less studied $[8,19,20]$, and is often embedded and analysed as part of the 'other' or 'external' causes of diseases, which also include conditions such as accidents and injuries, poisoning, and exposure to other forces of nature.

These heat-related conditions are often poorly recognised and ill-defined but capture those patients who may be physiologically distressed as a result of the effects of heat but do not fit into other diagnoses. Heat-related conditions can lead to severe consequences, sometimes even deaths [21]. They not only affect the health of the people, but also increase the burden on the health systems including the emergency health services $[7,22]$. It is therefore important to analyse the prevalence of heatrelated conditions as a separate category in a region, rather than as a component of other diseases. Additionally, the monitoring of the presentation to the health care system 
of these conditions during heatwaves can provide timely surveillance information to improve decision-making, and target resources to where they are mostly required [23].

Public hospital emergency departments (EDs) are increasingly used by patients for a wide variety of conditions [24], and have been proven to be a useful surveillance tool to monitor the public health effects of heat events $[25,26]$. Despite a considerable amount of research on the effects of heat on mortality and health service utilisation in Brisbane [12-16,18], none have examined the effects of heat on daily ED presentations for conditions such as heatstroke and sun exposure. This study examines the association between heatwaves and the number of ED visits for heat illnesses further broken down by patients' demographic characteristics, the acuity of their conditions and treatment outcomes.

\section{Materials and methods}

\section{Study area}

The study was conducted within the greater Brisbane area, a subtropical city located in South East Queensland, Australia. One ED was excluded due to incomplete data. The EDs were located in the Local Government Areas of Brisbane, Ipswich, Logan, Moreton Bay and Redland (Figure 1). In 2011-12, the greater Brisbane area had an estimated 2.2 million inhabitants, with an average annual growth rate of $2.4 \%$, which has remained stable over the past decade [27].

\section{Heatwave definition}

There is no official heatwave definition for Brisbane, and no universally accepted definition is available [18]. Therefore, following previous studies in this city [14,28,29], we adopted two measures, that is periods of at least two consecutive days having a daily maximum temperature $\geq 34^{\circ} \mathrm{C}$ (HWD1) or $\geq 37^{\circ} \mathrm{C}$ (HWD2). These thresholds closely match the $95^{\text {th }}$ and $99^{\text {th }}$ percentiles of maximum temperature (Tmax) in Brisbane for the study period.

\section{Study period and data}

ED data for fiscal years of 2000 to 2012 for public hospital EDs in the greater Brisbane area were obtained from Queensland Health, which included 12 hospitals. One hospital was excluded as it only had ED data for 2007 to 2012; thus 11 EDs were included in this study.

The health data included de-identified records of daily presentations containing ICD codes, age, gender, triage category, dates and times of arrival and departure, and departure status. ICD codes for heat-related illnesses

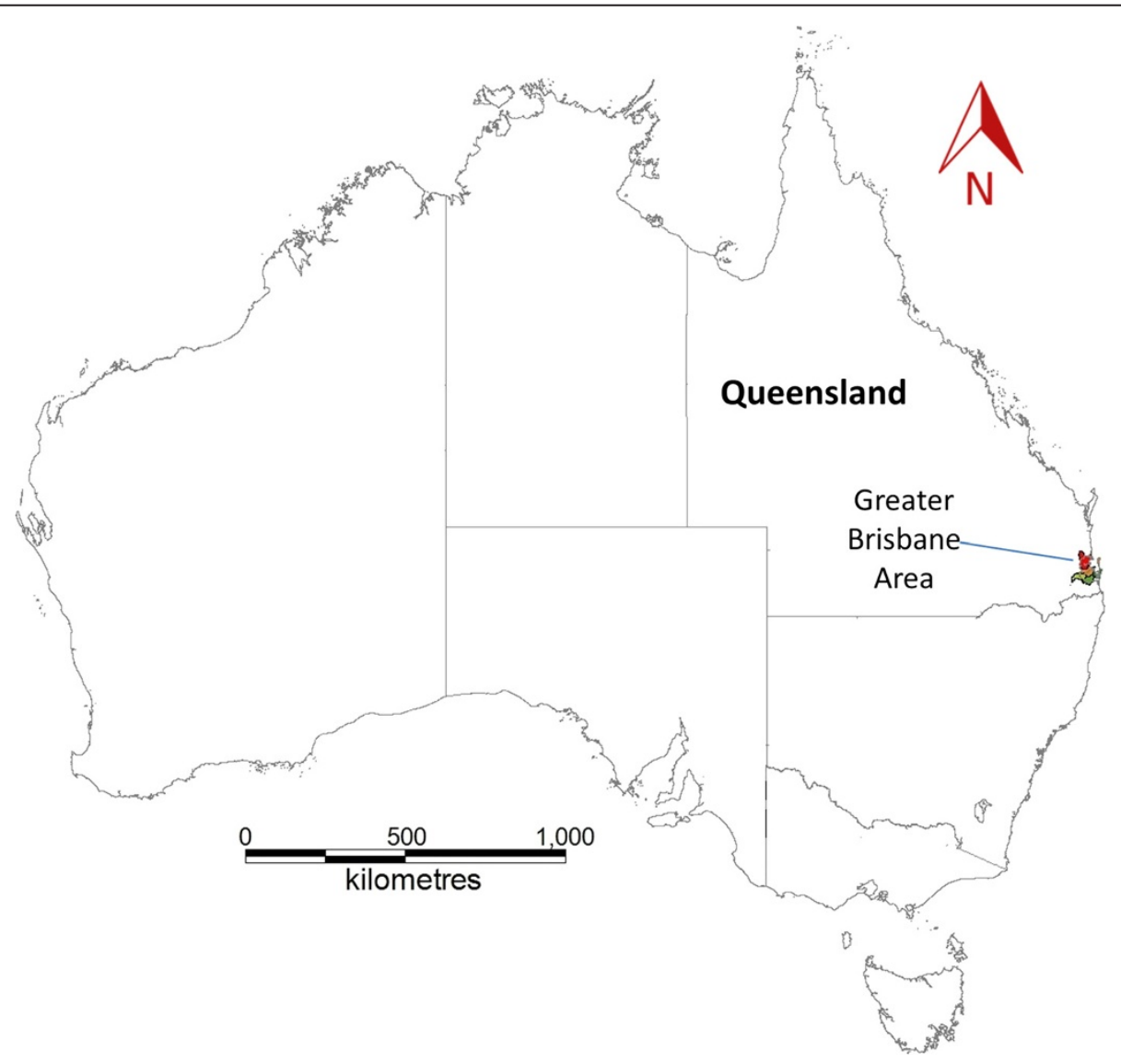

Figure 1 Map of the study area. 
included: effects of heat and light such as heatstroke, sunstroke, heat syncope and heat exhaustion (ICD 10 code T67; ICD 9 code 992), and exposure to excessive natural heat (ICD 10 code X30; ICD 9 code E900.0). Since there were only eight cases with exposure to excessive natural heat, we combined these with the heatstroke group. We did not include dehydration because the dataset did not contain specific codes for dehydration. As previous studies show the heat effects vary across age groups $[14,15,30]$, we re-coded age into four groups of 0 to 14 years, 15 to 64 years, 65 to 74 years, and $75+$ years. ED patients are triaged at arrival for acuity of their conditions based on the Australian triage scale from 1 to 5 , with 1 requiring immediate attention and 5 requiring care within 120 minutes [31]. For analysis purposes, we re-coded triage into three groups: 1 to 2 (high acuity), 3 (moderate), and 4 to 5 (low acuity). Departure status was provided as admitted or discharged. Length of stay in ED was calculated based on the time lapse between arrival and departure.

Daily Tmax and 24-hour average relative humidity data were obtained from the Bureau of Meteorology. Air pollution data including 24-hour average daily amounts of ozone $\left(\mathrm{O}_{3}\right)$, particulate matter with $<10$ micrometers in aerodynamic diameter $\left(\mathrm{PM}_{10}\right)$ and nitrogen dioxide $\left(\mathrm{NO}_{2}\right)$ were provided by the Department of Science, Information Technology, Innovation and the Arts.

\section{Statistical analysis}

The days were coded based on their Tmax and heatwave definition into three categories: non-hot day, single hot day, and heatwave day. We first assessed the difference in daily average number of ED presentations across these categories during the study period 2000 to 2012. We then recoded days as heatwave or non-heatwave, and used a poisson generalised additive model to examine the effect of heatwaves on ED visits after adjusting for potential confounders. We applied the generalised additive model as follows:

$$
\operatorname{Ln}\left(E\left(Y_{t}\right)=\alpha+\sum_{i=1}^{p}\left(\beta_{i} x_{i}\right)+n s(m, 4)+n s(y, 4)+\sum_{j=1}^{q} s\left(x_{j}, 4\right)\right.
$$

Where $t$ refers to the day of the observation; $\left(Y_{t}\right)$ denotes the observed disease counts on day $t ; x_{j}$ denotes the smooth function of relative humidity, $\mathrm{O}_{3}, \mathrm{PM}_{10}$ and $\mathrm{NO}_{2} ; m$ and $y$ are the month and year, and natural cubic splines with 4 degrees of freedom were used to adjust for seasonal and long-term effects; $x_{i}$ denotes the characteristic factors of the day of the week and heatwaves; $\alpha$ is the intercept term; $\beta$ is the coefficient.

We then calculated the relative risks (RR) and 95\% CI of attending on heatwave days versus non-heatwave days (non-hot and single hot days combined) by demographic and visit characteristics (acuity and discharge status). Analysis was restricted to summer months (December, January and February) to avoid the confounding effects of seasonality. To describe the RRs in the text, we have rounded the figures to one decimal point (rounded down if the second decimal digit was $\leq 5$; rounded up if it was $>5$ ). The RR is reported as the number of times the risk increases. For example, $R R=4.98$ is reported as 5 times. All analyses were performed in SPSS Statistics 21.0 (IBM Software, New York, USA) and R3.0.1 (R Foundation, Vienna, Austria).

Ethical approvals were granted by Queensland University of Technology Human Research Ethics Committee and Queensland Health Research Ethics Committee. As the data were provided in de-identified form, both committees waived the need for patient consent.

\section{Results}

Table 1 shows low to moderate correlation between each pair of the environmental variables. Relative humidity was inversely associated with Tmax, $\mathrm{O}_{3}$ and $\mathrm{PM}_{10}$. $\mathrm{NO}_{2}$ was weakly but positively associated with $\mathrm{PM}_{10}$.

Tmax ranged between $20.3^{\circ} \mathrm{C}$ and $40.2^{\circ} \mathrm{C}$ during the study period (Table 2) with a mean of $29.8^{\circ} \mathrm{C}$ (95\% CI: $29.6^{\circ} \mathrm{C}, 29.9^{\circ} \mathrm{C}$ ). Relative humidity ranged between $20.8 \%$ and $95.8 \%$ with a mean of $59.9 \%$ (95\% CI: $59.2 \%, 60.6 \%$ ). The daily mean was $0.02 \mathrm{ppm}(95 \% \mathrm{CI}: 0.02,0.02)$ for $\mathrm{O}_{3}, 18.4 \mu \mathrm{g} / \mathrm{m}^{3}$ (95\% CI: $\left.18.0,18.8\right)$ for $\mathrm{PM}_{10}$, and $<0.01$ ppm (95\% CI: 0.00, 0.00) for $\mathrm{NO}_{2}$.

Of the 1,151 ED presentations for heat illnesses between 2000 and 2012, 628 cases (54.6\%) occurred during summer periods. Figure 2 shows that the relative risk of heat-related illness visits increased with increasing temperatures. There appeared to be a more or less linear relation between ED presentations and Tmax between $30^{\circ}$ $\mathrm{C}$ and $36^{\circ} \mathrm{C}$, after which it became supra-linear.

Table 3 shows the number of presentations on nonhot, single hot and heatwave days. There were 19 single hot and 30 heatwave days from 2000 to 2012 in December to February based on HWD1, and two single hot and five heatwave days based on HWD2. The average of Tmax reached $35.5^{\circ} \mathrm{C}$ and $38.8^{\circ} \mathrm{C}$ during the heatwave days according to HWD1 and HWD2, respectively.

Table 1 Spearman's correlation between environmental variables, December to February 2000 to 2012

\begin{tabular}{lcccc}
\hline & Tmax & Relative humidity & $\mathbf{O}_{3}$ & $\mathbf{P M}_{10}$ \\
\hline Relative humidity & $-0.35^{* *}$ & & & \\
$\mathbf{O}_{3}$ & $0.26^{* *}$ & $-0.31^{* *}$ & & \\
$\mathbf{P M}_{10}$ & $0.33^{* *}$ & $-0.29^{* *}$ & $0.36^{* *}$ & \\
$\mathrm{NO}_{2}$ & -0.02 & 0.04 & -0.03 & $0.13^{* *}$ \\
\hline
\end{tabular}

**P $P<0.01$ (two-tailed). Number of days: 1,083. Tmax, daily maximum temperature in centigrade; $\mathrm{O}_{3}$, ozone; $\mathrm{PM}_{10}$, particulate matter with $<10$ micrometers in aerodynamic diameter; $\mathrm{NO}_{2}$, nitrogen dioxide. 
Table 2 Descriptive characteristics of environmental variables, December to February 2000 to 2012

\begin{tabular}{lccccc}
\hline & $\begin{array}{c}\text { Tmax } \\
\left({ }^{\circ} \mathbf{C}\right)\end{array}$ & $\begin{array}{c}\text { Relative } \\
\text { humidity }(\%)\end{array}$ & $\begin{array}{c}\mathbf{O}_{3} \\
(\mathbf{p p m})\end{array}$ & $\begin{array}{c}\mathrm{PM}_{10} \\
\left(\boldsymbol{\mu g} / \mathbf{m}^{3}\right)\end{array}$ & $\begin{array}{c}\mathbf{N O}_{2} \\
(\mathbf{p p m})\end{array}$ \\
\hline Mean & 29.83 & 59.90 & 0.02 & 18.43 & $<0.01$ \\
$(95 \% \mathrm{Cl})$ & $(29.68,29.97)$ & $(59.21,60.59)$ & $(0.02,0.02)$ & $(18.03,18.83)$ & $(0.00,0.00)$ \\
SD & 2.43 & 11.90 & 0.01 & 6.71 & 0.00 \\
Minimum & 20.32 & 20.83 & 0.00 & 4.70 & 0.00 \\
Maximim & 40.20 & 95.83 & 0.04 & 81.31 & 0.01 \\
Median & 29.72 & 58.20 & 0.01 & 17.57 & 0.00 \\
95 pct & 33.92 & 82.44 & 0.03 & 29.74 & 0.01 \\
99 pct & 36.47 & 89.41 & 0.03 & 44.30 & 0.01 \\
\hline
\end{tabular}

Tmax, daily maximum temperature in centigrade; $\mathrm{O}_{3}$, ozone; $\mathrm{PM}_{10}$, particulate matter with $<10$ micrometers in aerodynamic diameter; $\mathrm{NO}_{2}$ nitrogen dioxide; $95 \mathrm{pct}$, 95 th percentile; $99 \mathrm{pct}$, 99th percentile.

Compared to non-heatwave days, the relative risks of heat-related illness visits on heatwave days increased 5.0 times (95\% CI: 3.9, 6.4) and 18.5 times (95\% CI: 12.0 , 28.5) based on HWD1 and HWD2, respectively.

Table 4 shows the mean daily presentations and relative risks by patients' demographic characteristics. Based on HWD1, females and males had 4.5 (95\% CI: 3.1, 6.6) and 5.3 (95\% CI: 3.8, 7.4) times more risk of ED visits with heat illness on heatwave versus non-heatwave days, respectively. However, based on HWD2, the relative risks increased 17.8 (95\% CI: 9.8, 32.4) and 19.6 times (95\% CI: 11.2, 34.4) for females and males, respectively.

Regarding age, based on HWD1, the relative risks of presentations with heat illness on heatwave days increased 3.0 times (95\% CI: 1.2, 7.6) for ages 0 to 14 years, 3.6 times (95\% CI: $2.6,5.2)$ for ages 15 to 64 years, 7.3

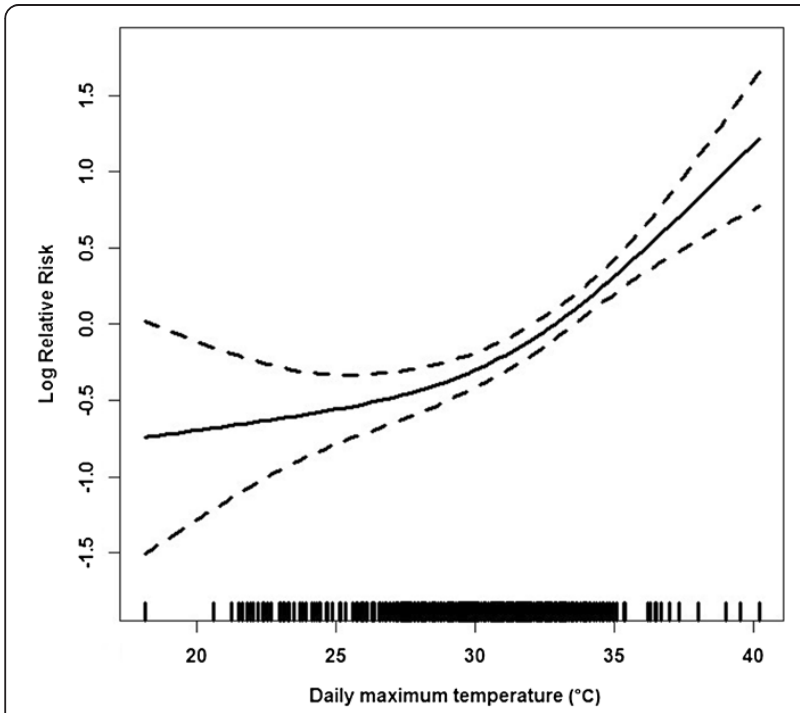

Figure $\mathbf{2}$ The association between daily maximum temperature in centigrade (Tmax) and emergency department (ED) presentations, December to February 2000 to 2012. times (95\% CI: $3.9,13.5)$ for ages 65 to 74 years, and 9.2 times (95\% CI: 5.4, 15.4) for ages 75 years and above. On the other hand, based on HWD2, the relative risks increased 29.8 times (95\% CI: 7.3, 122.6), 7.5 times (95\% CI: 3.9, 14.2), 23.5 times (95\% CI: 9.0, 61.7) and 37.5 times (95\% CI: 18.3, 76.9) for ages 0 to 14 years, 15 to 64 years, 65 to 74 years and $75+$ years, respectively.

Considering the indigenous status, only $11(1.7 \%)$ patients were identified as indigenous. Based on HWD1, the increases were not statistically significant, and based on HWD2, all indigenous patients attended with heat illness on non-hot days. For the non-indigenous patients, the relative risks increased 4.9 (95\% CI: 3.8, 6.3) times according to HWD1, and 18.3 times (95\% CI: 11.8, 28.2) based on HWD2.

Table 5 shows average daily presentations and relative risks by illness characteristics. Based on HWD1, the relative risks of presentations with high, moderate and low acuity increased nearly five times on heatwave days. However, based on HWD2, the relative risks increased 81.7 times (95\% CI: $21.5,310.0)$ in the high acuity category, 17.2 times (95\% CI: 9.4, 31.6) in the moderate category, and 9.9 times (95\% CI: 5.2, 19.1) in the low acuity group. Regarding the departure status, based on HWD1, the relative risks of admission or discharge increased almost equally at close to five times. However, based on HWD2, the relative risk of admission with heat illness increased 31.3 times (95\% CI: 15.2, 64.4) and the risk of discharges increased 14.7 times (95\% CI: 8.2, 26.2). The average length of stay in the ED with heat illness also increased significantly on heatwave versus non-heatwave days by over one hour based on HWD1, and over two hours based on HWD2.

\section{Discussion}

This is the first study oF heat illness and ED visits associated with heatwaves in Brisbane, and complements previous work on the effects of heat on mortality, hospital admissions and ambulance utilisation in this subtropical climate [13-16]. Our results show that as the temperature increased so did the likelihood by all gender and age groups of attending EDs with heat-related illness. It also confirms that the magnitude of impact can greatly vary by how a heatwave is defined [18]. For instance, based on HWD1, the relative risks increased three times in the 0 to 14 years age group, whereas based on HWD2, the impact elevated by 29 times. Similarly in the oldest age group (age 75 years and older), the RR increased from 9 to 37 times according to HWD1 and HWD2, respectively. Although the impact by triage category (acuity) and departure status were similar based on HWD1, the risk of attending with a higher acuity condition based on HWD2 was much higher than the risk of attending with a lower acuity 
Table 3 ED presentations by non-hot, single hot and heatwave days, December to February 2000 to 2012

\begin{tabular}{|c|c|c|c|c|c|c|c|}
\hline & \multicolumn{3}{|c|}{ HWD1 } & \multicolumn{3}{|c|}{ HWD2 } & \multirow[b]{2}{*}{ Total } \\
\hline & Non-hot & Single hot & Heatwave & Non-hot & Single hot & Heatwave & \\
\hline Number of days & 1,034 & 19 & 30 & 1,076 & 2 & 5 & 1,083 \\
\hline Presentations & 479 & 34 & 115 & 556 & 9 & 63 & 628 \\
\hline Average/day & 0.46 & 1.79 & 3.83 & 0.52 & 4.50 & 12.60 & 0.58 \\
\hline$(95 \% \mathrm{Cl})$ & $(0.41,0.52)$ & $(0.95,2.63)$ & $(1.47,6.20)$ & $(0.48,0.56)$ & $(3.52,5.48)$ & $(1.06,24.14)$ & $(0.49,0.67)$ \\
\hline $\mathrm{RR}^{*}(95 \% \mathrm{Cl})$ & & $4.98(3.88,6.3$ & & & $53(12.05,28$ & & \\
\hline
\end{tabular}

*Relative risk, heatwave days versus non-heatwave days (non-hot + single hot), controlled for relative humidity, particulate matter with <10 micrometers in aerodynamic diameter, ozone, nitrogen dioxide, day of week and long-term trends.

condition. Furthermore, the chance of admission was double the chance of discharge on HWD2, and patients were considerably more likely to stay longer in the ED.

Consistent with the limited number of studies in this area, our findings confirm the health impact of heatwaves. Mayner et al. [32] showed that during the two heatwave periods in Adelaide, South Australia, in 2009, the number of heat-related presentations to one ED increased 21 and 17 times versus comparable pre-heatwave periods. Another study in Sydney, Australia, also found that ED visits with heat-related illnesses increased over seven times during the 2011 heatwave compared to the average number of such visits in previous years, with 100\% excess rate per
100,000 population amongst people aged $75+$ [33]. Other Australian studies show that hospital admissions for heatrelated conditions increased over three times in Sydney [19] and nearly six times in New South Wales [8] during extreme heat periods. Although both of these figures are close to the ED admissions in our study based on HWD1, they are far lower than the HWD2 figure (31.3 times). One reason may be that these studies also included volume depletion as a proxy for dehydration in their analyses. As volume depletion could happen on non-hot days as a result of other factors besides heat exposure (for example, strenuous activities), the inclusion may have affected the RR estimates. Furthermore, the differences show the extent to

Table 4 Mean daily emergency department presentations and relative risks by demographic characteristics, December to February 2000 to 2012

\begin{tabular}{|c|c|c|c|c|c|c|c|c|}
\hline & \multicolumn{4}{|c|}{ HWD1 } & \multicolumn{4}{|c|}{ HWD2 } \\
\hline & Non-hot & Single hot & Heatwave & $\mathbf{R R}^{*}$ & Non-hot & Single hot & Heatwave & $\mathbf{R R}^{*}$ \\
\hline \multicolumn{9}{|l|}{ Gender } \\
\hline Female & 0.19 & 0.89 & 1.60 & 4.55 & 0.21 & 4.00 & 5.60 & 17.79 \\
\hline$(95 \% \mathrm{Cl})$ & $(0.16,0.22)$ & $(0.30,1.49)$ & $(0.40,2.80)$ & $(3.13,6.61)$ & $(0.18,0.24)$ & $(2.04,5.96)$ & $(-0.55,11.75)$ & $(9.76,32.43)$ \\
\hline Male & 0.27 & 0.89 & 2.23 & 5.32 & 0.31 & 0.50 & 7.00 & 19.65 \\
\hline$(95 \% \mathrm{Cl})$ & $(0.23,0.31)$ & $(0.18,1.61)$ & $(0.97,3.49)$ & $(3.83,7.38)$ & $(0.27,0.35)$ & $(-0.48,1.48)$ & $(1.06,12.94)$ & $(11.22,34.42)$ \\
\hline \multicolumn{9}{|c|}{ Age group, years } \\
\hline 0 to 14 & 0.06 & 0.11 & 0.2 & 3.00 & 0.06 & 0.50 & 0.80 & 29.85 \\
\hline$(95 \% \mathrm{Cl})$ & $(0.04,0.08)$ & $(-0.03,0.25)$ & $(0.03,0.37)$ & $(1.19,7.56)$ & $(0.05,0.07)$ & $(-0.48,1.48)$ & $(0.07,1.53)$ & $(7.27,122.56)$ \\
\hline 15 to 64 & 0.29 & 1.26 & 1.63 & 3.64 & 0.32 & 3.50 & 4.00 & 7.49 \\
\hline$(95 \% \mathrm{Cl})$ & $(0.25,0.33)$ & $(0.58,1.94)$ & $(0.87,2.39)$ & $(2.56,5.18)$ & $(0.28,0.36)$ & $(2.52,4.48)$ & $(0.78,7.22)$ & $(3.93,14.25)$ \\
\hline 65 to 74 & 0.05 & 0.26 & 0.67 & 7.29 & 0.06 & 0 & 2.20 & 23.54 \\
\hline$(95 \% \mathrm{Cl})$ & $(0.04,0.06)$ & $(0.01,0.51)$ & $(0.25,1.09)$ & $(3.93,13.53)$ & $(0.04,0.08)$ & - & $(0.63,3.77)$ & $(8.99,61.69)$ \\
\hline $75+$ & 0.07 & 0.16 & 1.33 & 9.17 & 0.08 & 0.50 & 5.60 & 37.55 \\
\hline$(95 \% \mathrm{Cl})$ & $(0.05,0.09)$ & $(-0.01,0.33)$ & $(0.01,2.65)$ & $(5.45,15.44)$ & $(0.06,0.1)$ & $(-0.48,1.48)$ & $(-1.67,12.87)$ & $(18.34,76.86)$ \\
\hline \multicolumn{9}{|c|}{ Indigenous status } \\
\hline Indigenous & 0.01 & 0 & 0.03 & 1.63 & 0.01 & 0 & 0 & 0 \\
\hline$(95 \% \mathrm{Cl})$ & $(0,0.02)$ & - & $(-0.04,0.1)$ & $(0.14,19.13)$ & $(0,0.02)$ & - & - & - \\
\hline Non-indigenous & 0.44 & 1.79 & 3.77 & 4.91 & 0.50 & 4.50 & 12.40 & 18.28 \\
\hline$(95 \% \mathrm{Cl})$ & $(0.39,0.49)$ & $(0.95,2.63)$ & $(1.4,6.14)$ & $(3.82,6.31)$ & $(0.44,0.56)$ & $(3.52,5.48)$ & $(0.71,24.09)$ & $(11.85,28.22)$ \\
\hline
\end{tabular}

*Relative risk, heatwave days versus non-heatwave days (non-hot + single hot), controlled for relative humidity, particulate matter with $<10$ micrometers in aerodynamic diameter, ozone, nitrogen dioxide, day of week and long-term trends. - not applicable. 
Table 5 Average daily emergency department presentations and relative risks by illness characteristics, December to February 2000 to 2012

\begin{tabular}{|c|c|c|c|c|c|c|c|c|}
\hline & \multicolumn{4}{|c|}{ Heatwave day $\geq 34^{\circ} \mathrm{C}$} & \multicolumn{4}{|c|}{ Heatwave day $\geq 37^{\circ} \mathrm{C}$} \\
\hline & Non-hot & Single hot & Heatwave & $\mathrm{RR}^{*}$ & Non-hot & Single hot & Heatwave & $\mathrm{RR}^{*}$ \\
\hline \multicolumn{9}{|c|}{ Acuity (triage) } \\
\hline High (1 to 2 ) & 0.04 & 0.16 & 0.63 & 4.69 & 0.04 & 0.50 & 3.80 & 81.72 \\
\hline $95 \% \mathrm{Cl}$ & $(0.03,0.06)$ & $(-0.01,0.33)$ & $(-0.23,1.49)$ & $(2.30,9.57)$ & $(0.03,0.06)$ & $(-0.48,1.48)$ & $(-0.73,8.33)$ & $(21.54,310.01)$ \\
\hline Moderate (3) & 0.28 & 0.89 & 1.83 & 4.89 & 0.31 & 1.50 & 5.20 & 17.21 \\
\hline $95 \% \mathrm{Cl}$ & $(0.24,0.32)$ & $(0.26,1.53)$ & $(0.9,2.77)$ & $(3.47,6.89)$ & $(0.27,0.35)$ & $(-1.44,4.44)$ & $(1.21,9.19)$ & $(9.37,31.62)$ \\
\hline Low (4 to 5) & 0.14 & 0.74 & 1.37 & 4.84 & 0.16 & 2.50 & 3.60 & 9.95 \\
\hline $95 \% \mathrm{Cl}$ & $(0.11,0.16)$ & $(0.27,1.21)$ & $(0.62,2.12)$ & $(3.16,7.42)$ & $(0.13,0.19)$ & $(-0.44,5.44)$ & $(0.01,7.19)$ & $(5.19,19.08)$ \\
\hline \multicolumn{9}{|c|}{ Departure status } \\
\hline Admitted & 0.09 & 0.42 & 1.33 & 5.16 & 0.10 & 2.00 & 5.80 & 31.31 \\
\hline $95 \% \mathrm{Cl}$ & $(0.07,0.11)$ & $(-0.01,0.85)$ & $(-0.04,2.71)$ & $(3.24,8.21)$ & $(0.08,0.12)$ & $(-1.92,5.92)$ & $(-1.72,13.32)$ & $(15.23,64.37)$ \\
\hline Discharged & 0.34 & 1.26 & 2.03 & 4.87 & 0.38 & 2.50 & 4.80 & 14.69 \\
\hline $95 \% \mathrm{Cl}$ & $(0.3,0.39)$ & $(0.5,2.03)$ & $(0.82,3.24)$ & $(3.51,6.77)$ & $(0.33,0.43)$ & $(-2.4,7.4)$ & $(-1.09,10.69)$ & $(8.22,26.24)$ \\
\hline \multicolumn{4}{|c|}{ Length of stay (hh:mm) } & $F$-test $(P)$ & & & & $F$-test $(P)$ \\
\hline Mean & $3: 47$ & $3: 20$ & $4: 45$ & 5.27 & 3:45 & $2: 26$ & $5: 53$ & 15.60 \\
\hline Minimum & $0: 08$ & $0: 44$ & $0: 21$ & $(0.005)$ & 0:08 & $0: 44$ & $1: 18$ & $(0.000)$ \\
\hline Maximum & $24: 42$ & $8: 34$ & $20: 55$ & & $24: 42$ & $4: 17$ & 20:54 & \\
\hline SD & $2: 54$ & $1: 43$ & $3: 53$ & & 2:48 & $0: 59$ & $4: 33$ & \\
\hline
\end{tabular}

*Relative risk, heatwave days versus non-heatwave days (non-hot + single hot), controlled for relative humidity, particulate matter with <10 micrometers in aerodynamic diameter, ozone, nitrogen dioxide, day of week and long-term trends.

which the heat effects depend on the location and measurement standards.

During the 2006 California heatwave, heat-related ED visits increased 6.3 times (95\% CI: 5.6, 7.0) and admissions 10.1 times (95\% CI: 7.7, 13.4) [34]. The same study reported that the age-specific ED visits increased 6.1, 5.4 and 10.8 times for age groups 0 to 4,5 to 64 and $65+$ years, respectively. Again, although these figures are close to HWD1 results, they are considerably lower than the HWD2 findings. In addition to differences in heatwave definition, the difference may be attributed to design differences, as the California study compared one heatwave period with a reference period using a descriptive approach, whereas our study used a time-series study design. Furthermore, population characteristics and community preparedness may explain some of the differences. The age groups were not directly comparable as the two studies used different age brackets, although both reported similar patterns.

Our study also showed that the heat effects varied across demographic characteristics. There are various possible explanations. Children may be more vulnerable due to lack of proper care and adaptation behaviour [30], whereas older patients may be more at risk due to a 'less developed thermoregulation or their low self-care ability', which may be compounded by health comorbidities [35]. Other factors, such as socio-economic status, living conditions, social support, working environment (for example, working outdoors during the day), and access to preventative and protective measures, may at least partly explain and contribute to the degree of exposure to risk and the effects of heatwaves [21,36-38].

Our data did not show any association between indigenous status and heat-related ED visits on hot or heatwave days based on HWD2. This is counter-intuitive as other studies show that indigenous communities are higher users of ED services than the non-indigenous [39], and are assessed to be highly vulnerable to climate change impacts due to chronic health conditions and lower socio-economic status [40]. There is no certain explanation for this finding. One speculation may be that due to higher prevalence of other diseases such as diabetes, cardiovascular and renal problems among the indigenous than non-indigenous groups [41], the presentation was not coded as a heatrelated illness, but as the underlying health condition (for example, renal problems) exacerbated by heat. It may also be hypothesized that the indigenous people are better adapted to heat. Further research is required to provide a conclusive response.

We also found that risks of high-acuity visits and admissions with heat illness increased disproportionately during extreme heatwaves (HWD2 compared to HWD1). This 
may be attributed to lack of preparedness, at least in some sections of the community, for extremely hot periods. Brisbane has lengthy periods of warm temperatures in summer, and most residents may be acclimatised and prepared for normally hot days. However, with changing climate, population aging and high rate of immigration in this region [27], such assumptions cannot be taken for granted. Currently, there is no research available to show how prepared different groups of people are in facing the warming climate in Queensland, including Brisbane. However, studies in other countries show that people who see themselves personally vulnerable are more likely to take action to protect against heat harm [42].

This study has major strengths. To our knowledge, this is the first study to examine the association of heatwaves with heat illnesses in a subtropical climate. As the health impacts of heatwaves are highly location-specific, this study contributes to understanding of the acute effects of heat in warmer locations. Second, although studies have shown that ED visits generally increase on heatwave days to some extent, our findings show that presentations with heat illness are disproportionately much higher than other illnesses. Finally, in addition to examining the heat illness visits, we analysed the impact of heatwaves on the acuity of the condition, admission status and length of stay. This enabled us to show a more accurate picture of how increasing temperatures can increase the health system workload and reduce bed capacity. On heatwave days, the average length of stay in the ED increased significantly, due potentially to an increased number of patients and higher severity of their conditions, as determined by higher RR of acuity and admission. These can have considerable implications for the emergency health system which is under constant pressure due to excess demand and overcrowding $[24,43]$.

The study had certain limitations. First, due to the unavailability of data, the study population was limited to patients attending 11 public hospital EDs and who were diagnosed as having heatstroke or related conditions. Patients using private EDs, primary care services, or those who did not seek care but were affected, were not included. These, plus exclusion of one ED due to incomplete data, underestimate the true extent of heatwave effects in Brisbane. In particular it does not include those in whom the heat has exacerbated other chronic or acute illnesses. Second, because of small numbers, we were unable to establish whether the indigenous group was affected differently during heatwaves. Only 11 cases $(1.7 \%)$ were identified as indigenous. More complete data and a larger sample are needed for such analyses. In addition, the non-indigenous group comprises patients from a wide range of other ethnic groups. Better and more detailed data are required to analyse ethnic differences based on these factors. Third, we could not obtain data such as patient's location at the time of illness, arrival method, comorbidities and follow-up data after admission to inpatient wards or discharge. Such data would have been able to provide a more comprehensive picture of the impact of heatwaves on patients and the emergency health system. Last, we did not have information on individual exposure to heat. Also it is likely that heatstroke may have been due to other heat sources, particularly on non-hot days. Such information can only be obtained through direct monitoring of patients, which was outside the scope of this study.

\section{Conclusions}

More patients and sicker patients (as determined by the increase in the average number and relative risk of presentation in high acuity categories) attend EDs during heatwaves and hot days, causing an extra workload for the emergency health system which is already under stress. Targeted protective measures are proven to assist with reducing these impacts [42]. ED data can be reliably used as a monitoring and surveillance tool for timely detection of the syndromes and early effects of heatwaves [26]. The data can be used to help the health service providers prepare for the potential effects, and to ensure that the limited resources are allocated to those who need them most.

\section{Key messages}

- Even in a subtropical climate where people are better acclimatised to warmer temperatures, hot temperatures and heatwaves can still have serious acute health effects on the population.

- The magnitude of impact varies across age groups. Children, young teenagers and the elderly are particularly vulnerable.

- Heat health warning, protection and intervention plans and protocols should be developed to respond to heatwave impacts, advise the community of the health dangers, and implement strategies to minimise the risk.

- Health education messages and programmes should specifically target these high risk groups and their carers, such as parents of young children, daycarers, retirees and independent living elderly, clubs and other relevant agencies to inform them of the risks and how to protect themselves.

- Health service providers including the EDs should prepare for and increase their surge and admission capacities to deal with the increase in demand for such services as a result of high temperatures, particularly as climate change progresses. 


\section{Abbreviations}

ED: emergency department; HWD1: heatwave day $\geq 34^{\circ} \mathrm{C}$; HWD2: heatwave day $\geq 37^{\circ} \mathrm{C}$; ICD: International Classification of Diseases; $\mathrm{NO}_{2}$ : nitrogen dioxide; $\mathrm{O}_{3}$ : ozone; $\mathrm{PM}_{10}$ : particulate matter with $<10$ micrometers in aerodynamic diameter; ppm: parts per million; Tmax: daily maximum temperature in centigrade.

\section{Competing interests}

The authors declare that they have no competing interests.

\section{Authors' contributions}

GT and ST conceived the study and participated in the design. GT, PA and GF contributed to the acquisition of data. GT and WY analysed and interpreted the data and prepared the first draft. GT, ST, PA and GF interpreted the results and revised the drafts. All authors critically reviewed the drafts for intellectual content. All authors have given approval of the final manuscript. All authors agree to be accountable for all aspects of the work in ensuring that questions related to the accuracy or integrity of any part of the work are appropriately investigated and resolved.

\section{Acknowledgements}

This study was funded by an Australian Research Council Linkage grant to ST (LP882699) in partnership with the Queensland Department of Environment and Resources Management, Queensland Health and the Environmental Protection Agency. GT and WY were employed as research fellows. ST was supported by an NHMRC research fellowship (\#553043). The funding bodies played no role in the design, collection, analysis, and interpretation of data; in the writing of the manuscript; and in the decision to submit the manuscript for publication. We also thank Mr Xin Qi, PhD candidate at the School of Public Health and Social Work, Queensland University of Technology, for preparing Figure 1.

Received: 30 October 2013 Accepted: 6 March 2014 Published: 9 April 2014

\section{References}

1. Tobias A, Armstrong B, Zuza I, Gasparrini A, Linares C, Diaz J: Mortality on extreme heat days using official thresholds in Spain: a multi-city time series analysis. BMC Public Health 2012, 12:133-141.

2. García-Herrera R, Díaz J, Trigo RM, Luterbacher J, Fischer EM: A review of the European summer heat wave of 2003. Crit Rev Environ Sci Technol 2010, 40:267-306.

3. Hajat S, Armstrong B, Baccini M, Biggeri A, Bisanti L, Russo A, Paldy A, Menne $B$, Kosatsky T: Impact of high temperatures on mortality: is there an added heat wave effect? Epidemiology 2006, 17:632-638.

4. Kyselý J, Kim J: Mortality during heat waves in South Korea, 1991 to 2005 : How exceptional was the 1994 heat wave? Clim Res 2009, 38:105-116.

5. Mastrangelo G, Hajat S, Fadda E, Buja A, Fedeli U, Spolaore P: Contrasting patterns of hospital admissions and mortality during heat waves: are deaths from circulatory disease a real excess or an artifact? Med Hypotheses 2006, 66:1025-1028.

6. Robine J-M, Cheung SLK, Roy SL, Oyen HV, Griffiths C, Michel J-P, Herrmann FR: Death toll exceeded 70,000 in Europe during the summer of 2003. C R Biol 2008, 331:171-178.

7. Dhainaut JF, Claessens YE, Ginsburg C, Riou B: Unprecedented heat-related deaths during the 2003 heat wave in Paris: consequences on emergency departments. Crit Care 2004, 8:1-2.

8. Khalaj B, Lloyd G, Sheppeard V, Dear K: The health impacts of heat waves in five regions of New South Wales, Australia: a case-only analysis. Int Arch Occup Environ Health 2010, 83:833-842.

9. Kovats RS, Ebi KL: Heatwaves and public health in Europe. Eur J Public Health 2006, 16:592-599.

10. Loughnan ME, Nicholls N, Tapper NJ: The effects of summer temperature, age and socioeconomic circumstance on acute myocardial infarction admissions in Melbourne, Australia. Int J Health Geogr 2010, 9:41-51.

11. McGeehin MA, Mirabelli M: The potential impacts of climate variability and change on temperature-related morbidity and mortality in the United States. Environ Health Perspect 2001, 109:185-189.

12. Huang $C$, Barnett $A G$, Wang $X$, Tong $S$ : The impact of temperature on years of life lost in Brisbane, Australia. Nat Clim Change 2012, 2:265-270.
13. Tong S, Ren C, Becker N: Excess deaths during the 2004 heatwave in Brisbane, Australia. Int I Biometeorol 2010, 54:393-400.

14. Wang X-Y, Barnett AG, Yu W, FitzGerald G, Tippett V, Aitken P, Neville G, McRae $D$, Verrall $K$, Tong $S$ : The impact of heatwaves on mortality and emergency hospital admissions from non-external causes in Brisbane, Australia. Occup Environ Med 2012, 69:163-169.

15. Yu W, Vaneckova P, Mengersen K, Pan X, Tong S: Is the association between temperature and mortality modified by age, gender and socio-economic status? Sci Total Environ 2010, 408:3513-3518.

16. Turner LR, Connell D, Tong S: Exposure to hot and cold temperatures and ambulance attendances in Brisbane, Australia: a time-series study. BMJ Open 2013, 2:e001974.

17. Ren C, Williams $G M$, Tong $S$ : Does particulate matter modify the association between temperature and cardiorespiratory diseases? Environ Health Perspect 2006, 114:1690-1696.

18. Tong $S$, Wang $X Y$, Barnett AG: Assessment of heat-related health impacts in Brisbane, Australia: comparison of different heatwave definitions. PLOS ONE 2010, 5:e12155.

19. Vaneckova P, Bambrick H: Cause-specific hospital admissions on hot days in Sydney. PLOS ONE 2013, 8:e55459.

20. Semenza JC, McCullough JE, Flanders WD, McGeehin MA, Lumpkin JR: Excess hospital admissions during the July 1995 heat wave in Chicago. Am J Prev Med 1999, 16:269-277.

21. Kravchenko J, Abernethy AP, Fawzy M, Lyerly HK: Minimization of heatwave morbidity and mortality. Am J Prev Med 2013, 44:274-282.

22. Ng CFS, Ueda K, Ono M, Nitta H, Takami A: Characterizing the effect of summer temperature on heatstroke-related emergency ambulance dispatches in the Kanto area of Japan. Int J Biometeorol 2013, doi:10.1007/500484-013-0677-4

23. Claessens $Y$-E, Taupin P, Kierzek G, Jean-Louis P, Baud M, Ginsburg C, Jais J-P, Jougla E, Riou B, Dhainaut J-F, Landais P: How emergency departments might alert for prehospital heat-related excess mortality? Crit Care 2006, 10:R156-R156.

24. Fitzgerald G, Toloo S, Rego J, Ting J, Aitken P, Tippett V: Demand for public hospital emergency department services in Australia: 2000-2001 to 2009-2010. Emerg Med Australas 2012, 24:72-78.

25. Leonardi GS, Hajat S, Kovats RS, Smith GE, Cooper D, Gerard E: Syndromic surveillance use to detect the early effects of heat-waves: An analysis of NHS direct data in England. Soz Praventivmed 2006, 51:194-201.

26. Josseran $L$, Fouillet $A$, Caillère N, Brun-Ney D, llef D, Brucker $G$, Medeiros $H$, Astagneau P: Assessment of a syndromic surveillance system based on morbidity data: results from the Oscour ${ }^{\circledR}$ Network during a heat wave. PLOS ONE 2010, 5:e11984.

27. ABS: Regional Population Growth, Australia, 2011-12, cat. no. 3218.0; [http://www.abs. gov.au/ausstats/abs@.ns/Products/3218.0 2011-12 Main+Features Queensland? OpenDocument]. last updated 30/4/2013. [accessed: 20/8/2013]

28. Tong $S$, Wang $X-Y$, Guo $Y$ : Assessing the short-term effects of heatwaves on mortality and morbidity in Brisbane, Australia: comparison of case-crossover and time series analyses. PLOS ONE 2012, 7:e37500.

29. Turner $L R$, Connell $D$, Tong $S$ : The effect of heat waves on ambulance attendances in Brisbane, Australia. Prehospital Disaster Med 2013, 28:482-487.

30. $X u Z$, Sheffield PE, Su H, Wang $X, B i Y$, Tong S: The impact of heat waves on children's health: a systematic review. Int I Biometeorol 2013, 58:239-247.

31. ACEM: Guidelines for the Implementation of the Australasian Triage Scale in Emergency Departments [v3.0]. Australasian College for Emergency Medicine: 2013 [https://www.acem.org.au/getattachment/d19d5ad3-e1f4-4e4f-bf837e09cae27d76/G24-Implementation-of-the-Australasian-Triage-Scal.aspx]

32. Mayner L, Arbon P, Usher K: Emergency department patient presentations during the 2009 heatwaves in Adelaide. Collegian 2010, 17:175-182.

33. Schaffer A, Muscatello D, Broome R, Corbett S, Smith W: Emergency department visits, ambulance calls, and mortality associated with an exceptional heat wave in Sydney, Australia, 2011: a time-series analysis. Environ Health 2012, 11:3.

34. Knowlton K, Rotkin-Ellman M, King G, Margolis HG, Smith D, Solomon G, Trent R, English P: The, California heat wave: impacts on hospitalizations and emergency department visits. Environ Health Perspect 2009, 2006:61-67.

35. Kenny GP, Yardley J, Brown C, Sigal RJ, Jay O: Heat stress in older individuals and patients with common chronic diseases. Can Med Assoc J 2010, 182:1053-1060.

36. Martiello MA, Giacchi MV: High temperatures and health outcomes: a review of the literature. Scand J Public Health 2010, 38:826-837.

37. Kovats RS, Hajat S: Heat stress and public health: a critical review. Annu Rev Public Health 2008, 29:41-55. 
38. Schwartz J: Who is sensitive to extremes of temperature? A case-only analysis. Epidemiology 2005, 16:67-72.

39. Toloo S, Rego J, FitzGerald G, Aitken P, Ting J, Quinn J, Enraght-Moony E: Emergency Health Services: Demand and Service Delivery Models. Monograph 2: Queensland EHS Users' Profile. Brisbane QLD Australia: QUT; 2012 [http://eprints.qut.edu.au/55587/]

40. Green DL: Climate change and health: impacts on remote Indigenous communities in northern Australia. Australia: CSIRO; 2006 [http:/www.cmar.csiro.au/e-print/ open/greendl_2006.pdf]

41. MacRae A, Thomson N, Anomie, Burns J, Catto M, Gray C, Levitan L, McLoughlin N, Potter C, Ride K, Stumpers S, Trzesinski A, Urquhart B: Overview of Australian Indigenous health status 2012. WA, Australia: Australian Indigenous HealthInfoNet, Edith Cowan University; 2013 [http://www.healthinfonet.ecu.edu.au/health-facts/ overviews]

42. Toloo G, FitzGerald G, Aitken P, Verrall K, Tong S: Evaluating the effectiveness of heat warning systems: systematic review of epidemiological evidence. Int J Public Health 2013, 58:667-681.

43. Harris A, Sharma A: Access block and overcrowding in emergency departments: an empirical analysis. Emerg Med J 2010, 27:508-511.

doi: $10.1186 / \mathrm{cc} 13826$

Cite this article as: Toloo et al:: The impact of heatwaves on emergency department visits in Brisbane, Australia: a time series study. Critical Care 2014 18:R69.

\section{Submit your next manuscript to BioMed Central and take full advantage of:}

- Convenient online submission

- Thorough peer review

- No space constraints or color figure charges

- Immediate publication on acceptance

- Inclusion in PubMed, CAS, Scopus and Google Scholar

- Research which is freely available for redistribution 